\title{
Erratum to: Recruitment dynamics of the grove-dominant tree Microberlinia bisulcata in African rain forest: extending the light response versus adult longevity trade-off concept
}

\author{
David M. Newbery $\cdot$ Christophe J. Praz • \\ Xander M. van der Burgt • Julian M. Norghauer • \\ George B. Chuyong
}

Published online: 29 July 2010

(C) Springer Science+Business Media B.V. 2010

\section{Erratum to: Plant Ecol \\ DOI 10.1007/s11258-009-9631-2}

On page 163 (last complete paragraph) we omitted to mention in the text the mean agr of ht and nlv of small saplings in the main sample. Whilst $r g r$-values are shown in Fig. 7 those for $a g r$ are not. The missing ht and nlv values $( \pm$ SE), for 2003-2007, are $2.43 \pm$
$1.49 \mathrm{~cm} \mathrm{year}^{-1}$ and $-0.205 \pm 1.07$ year $^{-1}$, respectively $(n=45)$. The corresponding agr of stem dbh for large saplings is $0.578 \pm 0.171 \mathrm{~mm} \mathrm{year}^{-1}(n=$ 24). Now the comparison with the block sample rates in the first lines of page 164 is complete. The agrvalues are important for a population dynamics model to follow.
The online version of the original article can be found under doi:10.1007/s11258-009-9631-2.

D. M. Newbery $(\bowtie)$. C. J. Praz · X. M. van der Burgt .

J. M. Norghauer

Institute of Plant Sciences, University of Bern,

Altenbergrain 21, Bern 3013, Switzerland

e-mail: david.newbery@ips.unibe.ch

G. B. Chuyong

Department of Plant and Animal Sciences, University of

Buea, P. O. Box 63, Buea, SW Province, Cameroun

Present Address:

C. J. Praz

Department of Entomology, Cornell University, Ithaca,

NY 14853, USA

Present Address:

X. M. van der Burgt

Herbarium, Royal Botanic Gardens, Kew, Richmond,

Surrey TW9 3AB, UK 